\title{
Rabies in Children: Report of 24 Cases at the Yalgado Ouedraogo University Hospital Center of Ouagadougou in Burkina Faso
}

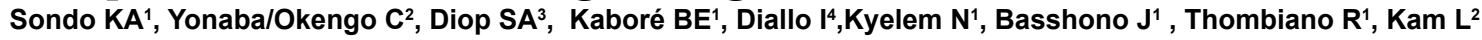 \\ ${ }^{1}$ Service of Infectious Diseases / Yalgado Ouédraogo University Hospital, Ouagadougou, Burkina Faso \\ ${ }^{2}$ Department of Pediatrics / Yalgado Ouédraogo University Hospital, Ouagadougou, Burkina Faso \\ 3Infectious Diseases Ibrahima Diop-Mar, National University Hospital Fann, Dakar, Unit training and health research, Thies University, Senegal \\ ${ }^{4}$ Service internal medicine / Yalgado Ouédraogo University Hospital, Ouagadougou, Burkina Faso
}

\begin{abstract}
Introduction/Objectives: Rabies is responsible for more than annual 55000 deaths in the world including 24000 in Africa. This study aims to study the epidemiological and clinical aspects of rabies in children at the University Hospital Center Yalgado Ouedraogo on 11 years.

Patients and Methods: This was a retrospective descriptive study of rabies cases in children who were received at CHUYO (University Hospital Center Yalgado Ouedraogo) from 1st January 2003 to 31 December 2014. The diagnosis was clinical, associated with a notion of suspect animal bite; data were collected from medical files and analyzed with Epi Info version 6.

Results: During the study period, 60 rabies cases were reported, including 24 children. Children average age was $08.5 \pm 4$ years with a sex ratio of 07 . In $47.6 \%$ of cases, children were referred from other provinces of the country and $58.3 \%$ case lived in rural areas. In all cases, the animal aggressor was a dog, and in $62.5 \%$ of cases, it was a stray dog. Upper limbs were the most common site followed by the lower limbs; nevertheless, the head represented $12.5 \%$ of the reported injuries. The main clinical signs were agitation (70.8\%), hydrophobia (58.3\%), and fever (50\%). In $30 \%$ of cases, the parents left the hospital with their child without or against medical opinion.
\end{abstract}

Conclusion: Rabies frequency is significant in children and is probably under-diagnosed because of clinical signs most often confused with other diseases. Pre-exposure prevention through vaccination is the best way to fight against rabies in children.

Keywords: Children rabies; Dog; Pre-exposure prevention

\section{Introduction}

Rabies is an anthropozoonosis responsible for an acute, primitive, and viral encelophalomyelitis. All warm-blooded animals are the pathogenic agent's reservoir [1]. According to the World Health Organization (WHO), rabies is enzootically present in more than one hundred and fifty (150) countries; and it is even estimated that rabies is responsible for more than fifty five thousand (55.000) deaths all over the world . This disease is especially raging in Asian, Africa, and South American countries $[2,3,4]$. After Asia, Africa is the second continent that is most affected by this zoonosis and counts for over twentyfour thousand (24.000) deaths a year, that is $44 \%$ in the world. WHO estimates that every twenty (20) minutes, a person dies from this disease in Africa $[2,5,6]$. In West Africa, rabies is still a permanent threat to the population. Rabies has a very heavy and socioeconomic impact on the populations' lives, because the post exposition management is enormously costly [5]. Burkina Faso is not an exception to this rule. The population, children above all live together with their dogs and other animals that are not vaccinated. A dog has many roles in a family, for it is the housekeeper and a good companion with whom children play. It helps hunt for game animals and rarely is this pet well taken care of and well fed, as it can be observed in developed countries. Very few studies are devoted to rabies in children. Children are the most threatened persons and the most infected by this disease according to WHO [5]. That is why this work was initiated, to study epidemiological and clinical aspects of rabies in children in Burkina Faso.

\section{Patients and methods}

\section{Study design and population}

This retrospective and descriptive study was conducted from $1^{\text {st }}$
January 2003 to $31^{\text {st }}$ December 2014. It concerned all children less than 15 years who were hospitalized for rabies in the department of infectious diseases of Yalgado Ouedraogo University Hospital Center (CHU-YO). This University Hospital Center (CHU) is a national reference hospital for all patients coming from all the regions of the country. It's composed of specialized services including infectious diseases. Burkina Faso has two other CHU and nine regional hospitals. In the study we were only interested in rabies cases referred to our hospital.

The following variables were studied: children's and parents' epidemiological characteristics (age, gender, residency, origin, parents profession, level of literacy); attacking animal's characteristics (nature, qualification, future, vaccinal status), the preventive actions taken by parents, clinical characteristics (time between animal bite and $1^{\text {st }}$ sign, bite location, the clinical signs), and the hospital discharge procedure.

\section{Diagnosis of rabies}

The diagnosis of rabies was based on history of non vaccinated animal bite associated to clinical signs hence hydrophobia, restlessness,

*Corresponding author: K Apoline Sondo, Centre Hospitalier Universitaire Yalgado Ouedraogo Ouagadougou, Kadiogo 01 BP 815 Ouagdougou 01, Burkina Faso, Tel: 0022676250418; E-mail: sondoapoline@yahoo.fr

Received July 01, 2015; Accepted July 21, 2015; Published July 28, 2015

Citation: Sondo KA, Okengo YC, Diop SA, Kaboré BE, Diallo I,et al. (2015) Rabies in Children: Report of 24 Cases at the Yalgago Ouedraogo University Hospital Center of Ouagadougou in Burkina Faso. J Trop Dis 3: 168 doi:10.4172/2329891X.1000168

Copyright: (c) 2015 Sondo KA. This is an open-access article distributed unde the terms of the Creative Commons Attribution License, which permits unrestricted use, distribution, and reproduction in any medium, provided the original author and source are credited. 
Citation: Sondo KA, Okengo YC, Diop SA, Kaboré BE, Diallo I,et al. (2015) Rabies in Children: Report of 24 Cases at the Yalgago Ouedraogo University Hospital Center of Ouagadougou in Burkina Faso. J Trop Dis 3: 168. doi:10.4172/2329891X.1000168

hypersialhoroea. No child had a diagnostic test for rabies because these tests were not available.

\section{Anti rabies vaccine protocol used in Burkina Faso}

After the bite, the wound must be cleaned with water and soap and the patient then goes to a health care center. Depending on the animal's vaccinal status, the anti-rabies vaccine is administrated. The post exposition protocol used in Burkina Faso is that of ESSEN. It's applied in 5 doses on D1, D3, D7, D14, D28 which costs about 76 Euros. Depending on the location of the bite (areas near the brain) and condition of the injury, rabies immunoglobulins should be administered but they are not available.

\section{Data management and statistical analysis}

The data from each patient were entered anonymous from the patients' medical files and analyzed with Epi Info version 6 software by descriptive statistics such as frequency distribution.

\section{Ethical consideration}

Ethics approval was not requested for this study ; The permission to use data was approved by local authorities of Yalgado Ouedraogo University Hospital (CHU-YO).

\section{Results}

\section{Epidemiological characteristics}

Sixty (60) cases of human rabies were recordered in the department of infectious diseases, classified as compatible with clinical human rabies. Twenty-four (24) cases of them were under 15 years (40\%) and were included in the study. The annual average number of cases was $4 \pm$ 2.9. The average age was $8.5 \pm 4$. They were 21 boys ( $87.5 \%)$ and 3 girls
(12.5\%) with a sex ratio=7. They were children of primary school (37.5) and preschool $(33,3 \%)$ mostly. Children lived in rural areas in $58.3 \%$. They came from Ouagadougou and it's peri urban areas (58.3) and from other provinces across the country in $41.7 \%$ (see figure $n^{\circ} 1$ ). Table 1 represents the children epidemiologicals characteristics.

\section{Characteristics of the children's parents}

The father was illiterate in $86.3 \%$ of the cases, and the mother in $90.9 \%$ of the cases. The mothers were all housewives and their fathers were farmers in $81.8 \%$ of the cases, traders in $9.1 \%$ of the cases and civil servants or drivers in $4.5 \%$ of the cases.

\section{Characteristics of the animals whom attacked children's}

The attacking animals were mostly dogs (100\%). They were stray dogs in $62.5 \%$ and these animals were killed in $58.3 \%$ of cases. The vaccinal status was unknown (66.7\%) and no animal was kept under observation, nor vaccinated. The attacking animal's characteristics are presented on table 2 .

\section{Clinical characteristics of the child infected with rabies}

The wounds were from bites in $91.5 \%$ of the cases and from claws in $8.5 \%$. The wounds were mostly found of the upper limbs (66.6\%) especially the hands in $58.3 \%$ of cases. However, the head represented $12.5 \%$ of the notified wounds. The main signs of rabies were agitation $70.8 \%$, hydrophobia (58.3) and fever (50\%). All children presented a spastic form of rabies. The average duration of incubation was 47 days \pm 32 with extremes ranging from 15 to 120 days. Table 4 shows the clinical findings of children.

In this study, $30 \%$ of the children left hospital without permission from the doctor and they later died.

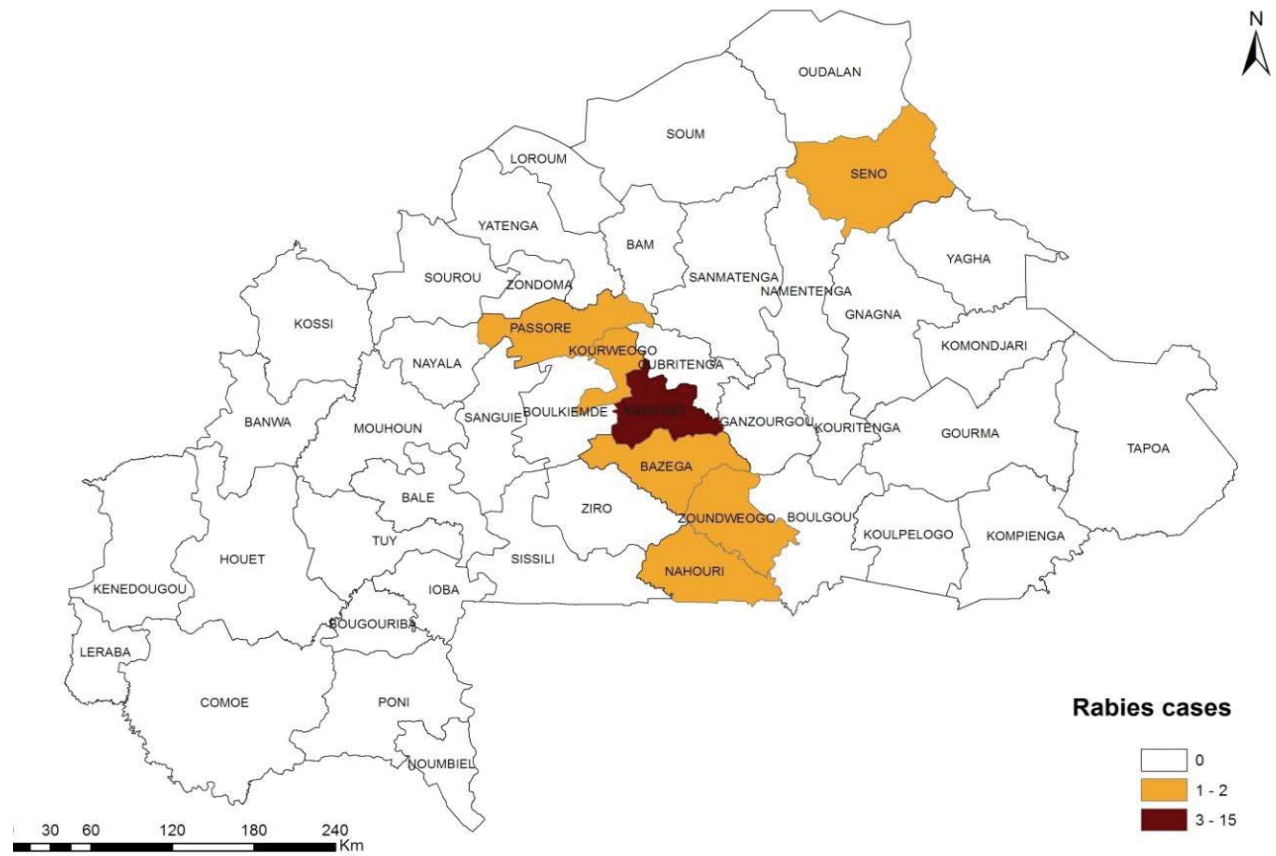

Figure 1: Cases of rabies at CHUYO: distribution in the provinces of Burkina Faso. 
Citation: Sondo KA, Okengo YC, Diop SA, Kaboré BE, Diallo I,et al. (2015) Rabies in Children: Report of 24 Cases at the Yalgago Ouedraogo University Hospital Center of Ouagadougou in Burkina Faso. J Trop Dis 3: 168. doi:10.4172/2329891X.1000168

Page 3 of 5

\begin{tabular}{|c|c|c|c|}
\hline $\begin{array}{l}\text { Socio- } \\
\text { epidemiological } \\
\text { Characteristics }\end{array}$ & & Numbers $\mathrm{N}=\mathbf{2 4}$ & (\%) \\
\hline \multirow{3}{*}{ Age group } & {$[0-5]$} & 8 & 33.3 \\
\hline & [5-10] & 6 & 25 \\
\hline & [5-10] & 10 & 41.7 \\
\hline \multirow{2}{*}{ Gender } & Male & 21 & 87.5 \\
\hline & Female & 3 & 12.5 \\
\hline \multirow{4}{*}{ Level of literacy } & Pre school & 8 & 33.3 \\
\hline & Non-school-goer & 3 & 12.5 \\
\hline & Primary & 9 & 37.5 \\
\hline & Secondary & 4 & 16.7 \\
\hline \multirow{2}{*}{ Region } & Centre & 14 & 58.3 \\
\hline & Other $^{*}$ & 10 & 41.7 \\
\hline \multirow{3}{*}{ Province } & Kadiogo" & 14 & 58.3 \\
\hline & Other"** & 10 & 41.7 \\
\hline & Rural & 14 & 58.3 \\
\hline Area of living & Urban & 10 & 41.7 \\
\hline
\end{tabular}

*Other regions: West Central, North, East Central, Sahel, Central Plateau**Ouagadougou and its peri urban areas ${ }^{* * *}$ Other provinces: Zoudweogo, Bazega, Boulkiemdé, Passoré, Boulgou, Ganzourgou, Kourweogo

Table 1: Rabies in children: distribution according to the socio epidémiological characteristics.

\begin{tabular}{|c|c|c|c|}
\hline $\begin{array}{c}\text { Attacking animal's } \\
\text { characteristics }\end{array}$ & Number & (\%) \\
\hline Animal's nature & Dog & 24 & 100 \\
\hline \multirow{2}{*}{ Animal's qualification } & Stray dog & 15 & 62.5 \\
\cline { 2 - 4 } & Domestic dog & 9 & 37.5 \\
\hline \multirow{2}{*}{ Animal's outcome } & Slaughtered & 14 & 58.3 \\
\cline { 2 - 4 } & Lost sight & 10 & 41.7 \\
\cline { 2 - 4 } & Veterinary observation & 0 & 0 \\
\hline \multirow{2}{*}{ Animal's vaccinal status } & Unknown & 16 & 66.7 \\
\cline { 2 - 4 } & Not vaccinated & 8 & 33.3 \\
\cline { 2 - 4 } & Vaccinated & 0 & 0 \\
\hline
\end{tabular}

Table 2: Distribution according to the attacking animal's characteristics.

\section{Actions taken by the parents after exposure}

After the animal aggression, five (5) parents (20.8\%) went to a health center and among them three (3) children received two doses of antirabies vaccine before the disease broke out. No patient had received rabies immunoglobulin. Thirteen (13) parents (54.1\%) sent their child to the traditional healer and five (5) children (20.8) had their wounds disinfected with water an soap at home. Five (5) children (20.8\%) had not informed their parents of the animal's bite. Table 4 represents the distribution of the children according to the post exposure actions taken by their parents.

\section{Discussion}

\section{Limits and constraints}

The inundation of the CHU-YO that took place on $1^{\text {st }}$ September 2009 made it impossible to exploit some files, which reduced the size of the sample. The retrospective aspect of the study explained the reason why some files were missing, but did not affected the quality of our results.

\begin{tabular}{|c|c|c|c|}
\hline $\begin{array}{c}\text { Clinical } \\
\text { characteristics }\end{array}$ & & Number & $(\%)$ \\
\hline \multicolumn{4}{|l|}{$\begin{array}{c}\text { Location of the } \\
\text { bite }\end{array}$} \\
\hline \multirow{3}{*}{ Head } & Ear & 1 & 4.1 \\
\hline & Eye & 2 & 8.3 \\
\hline & Total & 3 & 12.5 \\
\hline Abdomen & & 1 & 4.1 \\
\hline \multirow{4}{*}{ Upper limbs } & Hand & 14 & 58.3 \\
\hline & Arm & 1 & 4.1 \\
\hline & Shoulder & 1 & 4.1 \\
\hline & Total & 16 & 66.6 \\
\hline \multirow{3}{*}{ Lower limbs } & Thigh & 1 & 4.1 \\
\hline & Leg & 5 & 20.8 \\
\hline & Total & 6 & 25 \\
\hline \multirow{10}{*}{ Clinical signs } & Agitation & 17 & 70.8 \\
\hline & Hydrophobia & 14 & 58.3 \\
\hline & Fever & 12 & 50 \\
\hline & Hypersialorrhea & 11 & 45.8 \\
\hline & Headache & 10 & 41.6 \\
\hline & Vomiting & 7 & 29.1 \\
\hline & Delirium & 6 & 25 \\
\hline & Convulsion & 6 & 25 \\
\hline & Photophobia & 5 & 20.8 \\
\hline & Other $^{*}$ & 11 & 45.8 \\
\hline Clinical forms & Spastic rabies & 24 & 100 \\
\hline
\end{tabular}

Sweating, dyspnea, aggressiveness, skin rash, pruritus, insomnia

Table 3: Distribution of rabies cases according to clinical characteristics.

\begin{tabular}{|c|c|c|}
\hline $\begin{array}{l}\text { Post exposure actions taken by children } \\
\text { parents }\end{array}$ & Numbers $(n=24)$ & $(\%)$ \\
\hline \multicolumn{3}{|c|}{ Consultation at the traditional healer } \\
\hline Yes & 13 & 54.1 \\
\hline No & 11 & 45.9 \\
\hline \multicolumn{3}{|c|}{ Consultation in a health care center } \\
\hline Yes & 5 & 20.8 \\
\hline No & 19 & 79.2 \\
\hline \multicolumn{3}{|l|}{ Anti-rabic vaccine } \\
\hline Yes $^{*}$ & 3 & 12.5 \\
\hline No & 21 & 87.5 \\
\hline \multicolumn{3}{|l|}{ Rabies immunoglobulin } \\
\hline Yes & 0 & 0 \\
\hline No & 0 & 0 \\
\hline \multicolumn{3}{|l|}{ Local care at home } \\
\hline Yes $^{* *}$ & 5 & 20.8 \\
\hline No & 19 & 79.2 \\
\hline \multicolumn{3}{|c|}{ Parents 'information after animal 's bite } \\
\hline Yes & 19 & 79.2 \\
\hline No & 5 & 20.8 \\
\hline
\end{tabular}

* = two doses of vaccine in three children with bite in the head (eye, ear) $"=$ Washing the lesion with water and soap at home Table 4: Distribution of the cases according to the post exposure actions taken by the parents 


\section{Epidemiological characteristics}

The frequency of children rabies in the department of infectious diseases was $40 \%$. This result confirms the frequency of rabies estimated by WHO in children under 15 years in the world representing $30 \%$ to $60 \%$ of cases [7]. Some African authors founds the same things : Diop in Senegal reported in 2007 a frequency of $53.7 \%$ rabies cases in children aged 5 to 15 years; In Mali, Dao in 2006 noticed 6 children out of 10 cases of rabies. On the contrary, in Ivory Coast, Ouattara in 2007 reported a frequency lower than 2 children out 7 cases of rabies in a study conducted and carried out in 7 years $[8,97]$. In the Democratic Replublic of Congo, Muyila in 2014 had a very high frequency; he recorded twenty-one (21) cases of rabies in children in seven (7) months [10]. We estimate that there is not enough data of rabies in children especially in Burkina Faso. In other developing countries such as Madagascar, Rakotomala (1998) noticed in a national retrospective investigation conducted from 1985 to 2006 that one case of rabies out of two was not notified [11]. Many factors explain the lack of notification: the frequency of the similar clinical signs in children in other diseases such as meningitis, malaria, and typhoid fever. In addition, if the health care worker fails to orient interview towards a notion of an animal's bite, the long period of incubation of the disease may also make the child or the parents forget about this notion of animal bite. Very often, some parents are not well informed about their child having been bitten, which may make the diagnosis improbable. Finally, poverty, ignorance combined with cultural habits such as consultation at the traditional healer may result in a notification that is not well orientated. For all these reasons we believe that many cases of rabies have gone unnoticed.

Young persons could possibly be risk factors for rabies as children like playing with dogs; the vector of rabies are mainly animals [12]. Indeed we found mostly pre-school and primary school children in our study. They are the ones who are most at risk for the disease, because they ignore the danger of a dog bite. Therefore it is necessary to maintain a constant prophylactic treatment in children. The males predominated $(87.5 \%)$ with a higher frequency than in Muyila's study in Congo (51.7\%). This male predominance had been reported by the authors from Ivory Coast, Senegal, and Mali $[7,8,9]$. The sex ratio is higher in our study probably because little boys are the most exposed to the disease. They provoke dogs by throwing stones at them; they also like playing outdoors, sometimes far from their houses where they can meet stray dogs.

More than half of the children were from Ouagadougou and it peri urban areas; however a non negligible proportion $(41.7 \%)$ came from other regions across the country such as the West Central, North, East Central, and the Sahel. These regions are often remote places $100 \mathrm{~km}$ away from the CHU-YO and even further; and taking these infected children from these remote places to the CHU-YO can cost a lot, in term of transportation, hospitalization, and mortuary expenses. This situation is even more dramatic as the medical care is only palliative. To face such a situation it is recommended to train the health care workers in the different health center of the regions on how to manage the disease, in order to avoid useless references for rabies. In this study, $58.8 \%$ of the children lived in rural areas. The vulnerability of the population in the rural areas for rabies was pointed out by some authors in Africa: Diop in Dakar (88\%) and Dao in Bamako for all the cases of his study $[8,9]$. Promiscuity is frequent in the rural areas, which explains why animals and men are living together, which leads to the frequency of zoonoses in men. It has been demonstrated that rabies is a disease of poor and needy populations [13]. In actual fact, most of these children's parents were illiterate; their fathers were mainly farmers and their mothers were all housewives and jobless. In such a country as Burkina Faso, in which agriculture is still precarious, limited just to subsistence farming, most of the farmers are needy persons and are unable to pay anti rabies vaccine which costs 76 Euros. Which explains the lack of post exposure prevention in children in our study.

\section{Attacking animals characteristics}

The attacking animal was a dog in $100 \%$ and it was a stray dog in most of the cases (62.5\%). Muyila [10] in his study in children, found a higher proportion of the stray dog (90.5). Other authors also noted the role played by stray dogs in rabies in developing country [7-9, 14]. Indeed the dog is the main vector of human rabies in developing countries. Nevertheless, domestic dogs did play a non negligible role in the unexpected development of rabies in our study (37.5\%). These so-called domestics animals, are actually occasional stray dogs who keep wandering especially around dustbins and dumps for their food; that is where they meet stray dogs and get infected. The surrounding persons, especially children, become easy victims of their virulent bites. These dogs are most of the time neither vaccinated nor cared for. After biting, the stray dog or domestic dog ether disappear or is killed by the population; most of the time it is eaten by the population; this situation makes it impossible for a veterinary doctor to examine the dog. Muyila in Congo also found out the same situation as ours, where the aggressive dog is slaughted [10].

\section{Clinical aspects of rabies}

The wound was most of the time located on the upper limbs $(66.6 \%)$, most frequently on the hands (58.3\%). Most of the studies that were conducted on rabies showed a predominance of the lower limbs as frequent localizations whether with adults or children $[8,9]$. Muyila has noted a higher frequency in the legs (66.7\%), then the arms $(23.8 \%)$ in his study in children; probably because children in this study were older than in our study [10]. The three most frequents signs were agitation (70,8\%), hydrophobia (58.3) and fever (50\%); followed by headaches, fever, and vomiting. Our results confirm Muyali's higher frequencies. These symptoms are found in most infectious diseases in children in such as meningitis, malaria, and typhoid fever; these signs are found, and thus may mislead the diagnosis of rabies. On the other hand, all children had a spastic form of rabies. No case of paralytic rabies was noted. In Muyali's study, all the children got a furious rabies. This is a most common form of rabies in the population.

The study showed that $30 \%$ of the children had left hospital with or without a doctor's permission. The risk of interhuman transmission has not yet been described, but the virus is present in the saliva $[16,17]$; parents are permanently in contact with their child and they exposed to their bites. Once rabies diagnosis is established, patients should be isolated and treated in a health center, to minimize any close contact with the family. Management of rabies cases must be and should remain under the health care workers' responsibility. A psycho-medical management of the parents should also be considered because rabies inevitably evolves towards death.

\section{The post exposure actions taken by the children's parents}

None of the children received appropriate post-exposure prophylaxis. None of them had their wound clean after the exposure. In this study, $86.9 \%$ patients had not consulted health care center after being bitten by an animal; Diop in Senegal had found a lower frequency than ours $(77.8 \%)$ [8]. We agree with Tiembre in Côte d'Ivoire, who had found out that $56 \%$ of the patients exposed to an animal's bite, did not have their wound clean[ 18]. This procedure is the first basic step 
Citation: Sondo KA, Okengo YC, Diop SA, Kaboré BE, Diallo I,et al. (2015) Rabies in Children: Report of 24 Cases at the Yalgago Ouedraogo University Hospital Center of Ouagadougou in Burkina Faso. J Trop Dis 3: 168. doi:10.4172/2329891X.1000168

Page 5 of 5

in the post-exposure management [15]. The high rate of consultation to a traditional healer is a big obstacle to the management of rabies. [16]. In our study, no patient had received rabies immunoglobulin. Only three children (12.5\%) received an antirabies vaccine (ARV) after the bite and they were the one who had been bitten on the head. (eye and ear); because they did not immunoglobulin, they developed rabies. Some children did not inform their parents after the bite; but many of the parents who had been informed about their child's exposure and still they did not go to a health care center after the exposure. Probably either out of sheer negligence, ignorance of the seriousness of the disease, or lack of means, children developed rabies. The main reason for this situation is lack of resource. Most parents are poor and they can not bye the five regimen of antirabies vaccine. Muyali in Congo found the same results in his study [10]. The antirabic vaccine should therefore be imperatively subsidized and made available in all the regions of Burkina Faso. Rabies immunoglobulin is essential, especially when the bite is located on the head region or richly innervated area. The primary prevention is indispensable and the vaccination of the domestic animals should be made obligatory in Burkina Faso.

\section{Conclusion}

The frequency of rabies in children in the department of infectious diseases was $40 \%$ of all the rabies cases in our hospital. It was probably not diagnosed well enough in our context. The dog was the attacking animal since children are too close to animal pre-exposure anti rabies vaccine should be recommended and subsidized in children. It is necessary for the health care workers to be retrained in regard to rabies in order to avoid useless references. Burkina Faso's needs to should have laboratory tests for confirmation of human rabies; especially we should make available and accessible anti-rabies vaccine and rabies immunoglobulin.

\section{Authors' contribution}

All authors participated in the writing of this article and gave their consent to its submission. There is no conflict of interest to this report.

\section{References}

1. Bastin R, Charmot G, Frottier J, Vilde J.L (1981) Maladies Infectieuses et parasitaires ( $2^{\text {nd }}$ edtn) Flammarion Médecine Sciences ed. Paris.

2. Hance P, Garnotel E, Morillon M (2006) [Chiroptera and zoonosis: an emerging problem on all five continents]. Med Trop (Mars) 66: 119-124. [Article in French]

3. Ki-Zerbo GA, Kyelem N, Ouattara Y, Ouedraogo JP, Thiombiano R, et al. (2000) [Apropos of a case of rabies occurring despite vaccination after exposure]. Med Trop (Mars) 60: 67-69. [Article in French]

4. Nel LH, Rupprecht CE (2007) Emergence of lyssaviruses in the Old World: the case of Africa. Curr Top Microbiol Immunol 315: 161-193.

5. OMS (2001) Rage, Asie. REH 76: 320-332.

6. WHO (2005) WHO Expert Consultation on rabies. World Health Organ Tech Rep Ser 931: 1-88, back cover.

7. Ouattara SI, Cissé H, Kouakou G, Kolia-Diafouka P, Doumbia A, et al. (2012) [Human rabies in Abidjan (Côte d'Ivoire): recent cases]. Med Sante Trop 22: 157-161. [Article in French]

8. Diop SA, Manga NM, Dia NM, Ndour CT, Seydi M, et al. (2007) [The point on human rabies in Senegal from 1986 to 2005]. Med Mal Infect 37: 787-791. [Article in French]

9. Dao S, Abdillahi AM, Bougoudogo F, Toure K, Simbe C (2006) [Epidemiological aspects of human and animal rabies in the urban area of Bamako, Mali]. Bull Soc Pathol Exot 99: 183-186. [Article in French]

10. Muyila DI, Aloni MN, Lose-Ekanga MJ, Nzita JM, Kalala-Mbikay A, et al. (2014) Human rabies: a descriptive observation of 21 children in Kinshasa, the Democratic Republic of Congo Pathogens and Global Health 108 (7) 317-322.

11. Rakotomalala W, Rakotojanbelo A, Rakotoadrianomorales M, Roux J, Zeller H (1998) La rage humaine à Madagascar. Ann inst past Mad, 64 : 77-80.

12. OMS. Rage (2013) aide-mémoire $n^{\circ} 99$.

13. Dodet B, Africa Rabies Expert Bureau (AfroREB), Adjogoua EV, Aguemon AR, Amadou $\mathrm{OH}$, et al. (2008) Fighting rabies in Africa: the Africa Rabies Expert Bureau (AfroREB). Vaccine 26: 6295-6298.

14. Selly-Essis A, Chaw E, Dadou G, Angba A, Edoh V, et al. (1991) Aspects epidemiologiques de la rage dans le Département d'Abidjan. Med Afr 116: 11 16.

15. Nanayakkara S, Smith JS, Rupprecht CE (2003) Rabies in Sri Lanka: splendid isolation. Emerg Infect Dis 9: 368-371.

16. Benenson AS (1990) Control of communicable diseases in man. American Public Health Association, (15thedtn), Washington.

17. Dacheux L, Reynes JM, Buchy P, Sivuth O, Diop BM, et al. (2008) A reliable diagnosis of human rabies based on analysis of skin biopsy specimens. Clin Infect Dis 47: 1410-1417.

18. Tiembré I, Aka-Kone DM, Konan YE, Vroh JB, Kouadio DE, et al. (2009) [Adherence to rabies vaccine treatment for people exposed to rabies in Abidjan (Côte d' Ivoire)]. Sante Publique 21: 595-603. [Article in French] 